\title{
PERIODIZATION OF THE EAST ASIAN HISTORY OF SCIENCE
}

George Sarton in his Introduction to the History of Science called the early half of the 5th century the age of Faxian, and early 7th of Xuangzhuang, late 7th of Yizheng respectively. He did so rather conventionally, as he could not find any symbolic figure to represent the so-called Dark Age in the main current of Western scientific development. Unlike other figures in Western development, Chinese names do not necessarily represent notably high moments of Chinese achievements, or for that matter low ones. What is more telling in this context is, however, that while we are able to trace the centre of activities from ancient Babylonia, to classical Greece, to the Hellenistic world, to India, to the Islamic area and finally to Europe, China has been, throughout its history, very much isolated from the main current while she had remained the centre of East Asian cultural activity, including science, until the middle of 2 nd millenium. In such a tradition, the scheme of periodization of the history of science must necessarily be quite different, totally divorced from the Western historiography of science.

Apparently, China does not have any clear-cut " ancient-modern " dychotomy, as existed in the early modern West. The traditional way of periodizing Chinese history is to follow dynastic change modelled after official dynastic histories. Nearly all the Japanese works as edited by Professor Yabuuti follow this model, which is known as a chronological or dynastic history of science. Recent Chinese periodizations as summarized by Professor Xi Zezong in Chinese Science $(6,1983)$ are still basically rooted in dynastic periodization.

On the other hand, Joseph Needham's gigantic work Science and Civilization in China cares less for dynastic change and arranges the subjects according to the disciplines of modern science, thus making the comparison of Western and Chinese achievements more comprehensible for 
Western readers who are unfamiliar with dynastic periodization. Needham devoted his efforts to try to persuade the Western audience of Chinese scientific achievements, mainly by utilizing the historiography of Western history of science; his technique was to show that many Chinese works precede chronologically and were thus superior to their Western counterparts. This is perhaps the easiest way to claim Chinese priority in the history of discovery and invention.

Even with Needham's monumental works, however, it is still difficult to change the conventional way of eponymy ; for instance, we say " Qin Jinshao in the 13th century discovered Horner's method five centuries earlier than Horner ", rather than " Horner discovered Qin's method five centuries later than Qin "). This latter statement is meaningless if entered into a chronological table of discovery and invention arranged on a single track of positivistic progress.

Discoveries are, however, still measured by Western criteria. The Chinese must have had their own criteria by which to judge their achievements, and also they must have had an entirely different chronological scheme. For instance, in the mathematical tradition of East Asia, logical rigour has never been appreciated to the extent it was practiced in Euclidian and Aristotelian traditions in the West. Instead, they appreciated numerical precision on a decimal scale, which is sometimes incompatible with geometrical analog expression. So far in the West-dominated historiography of mathematics, the geometrical tradition has been a major trend in the history of mathematics, while the arithmetico-algebraic tradition like that of Qin Jinshao has been assigned a minor position. In this age of the computor digital, however, we may rewrite the history of mathematics by placing major emphasis on digital arithmetico-algebraic tradition, thus giving legitimate claims to the East Asian mathematical tradition. This is more than just a joke.

In the history of science, the language barrier plays a much more basic rôle than artificial national boundaries. Hence, we may classify science in terms of language employed, like Greek science, Latin science, Arabic science and also Chinese science. Thus, extant scientific works written in classical Chinese should all be classified into Chinese science, regardless of whether they were written by Korean, Japanese or people of any other nationality. It should be noted that in the research of the history of science, the nationality of the author is often hard to trace, while the language in which it was written is unmistakably clear.

If we do not limit our scope only to China, but extend it to include the whole area of Chinese cultural influence, including satellite countries like Korea, Annam and Japan, where classical Chinese was the main language by which scientific information was disseminated, we find it unne- 
cessary to follow Chinese dynastic periodization, as Chinese influence often reached neighbouring countries much later than the time when a scientific achievement was originally made in China. On the other hand, in order to find an indigenous way of periodization for the history of science, we have to depend on certain events or turning-points at which the internal structure of science underwent a great change, which gradually spread all over the Chinese-language area.

Unlike political history, however, it is hard to find a single-event turning-point encompassing various disciplines in the history of science. Taking all of these into consideration, I would like to suggest a new way of periodization of East Asian scientific tradition based on the characteristic approach in each period : 1 . Orientalist phase, 2. historical phase, 3. comparative phase and 4 . modern phase.

\section{Orientalist phase}

What is significant in the East Asian scientific tradition is that they share classics, or paradigms in Thomas Kuhn's sense. The Huangdi neijing and the Shanghan lun in medicine and the Zhoubi suanjing and the Jiuzhang suanshu in astronomy and mathematics were the real paradigms for all the Chinese-reading world. Most of these classics were formulated during the Han dynasty, though not all at once but through gradual additions and revisions. It may not be too far-fetched to assume that the formulation of paradigms must be somewhat related to the establishment of bureaucracy and also to the invention of writing technology like papermaking. In this area, we still have the possibility of reconsidering the history of science in the light of recently discovered or still undiscovered archeological evidence like the works of the late Professor Xia Nai.

Scholars working in the European tradition of Oriantalism, which started with a passion for the original and the oldest, were mainly interested in the pre-Han period and terminated their interest at the Han when the basic characteristics of Chinese science were formulated, as exemplified by the works of Henri Maspero. In Japanese studies on Chinese science also, the pre-war works of Shinjo Shinzo and Noda Churyo are classified as works in the Orientalistic tradition, while Yabuuti Kiyosi turned the study of Chinese science into history by working on the calendrical chapters of successive dynastic histories up to the Qing dynasty.

\section{Historical phase}

In contrast to a shift of the centre of activity from the Middle East to Western Europe, China always remained the centre of East Asian tradition up to the 19th century. Chinese bureaucracy and the early availability of paper may have contributed as stabilizing factors for the continuation and preservation of a continuous evolution of scientific deve- 
lopment. This makes it difficult to find the next turning-point. Though by no means a revolutionary break-through, we may take the Tang and Song periods as the point at which traditional Chinese science matured, since this was the age in which printing started and the civil service examination system was established. In some measure, the precision observation of astronomical parameters reached its zenith in Guo Shoujing's work of the Yuan dynasty. This is the period when the genuine Chinese scientific tradition came to its peak. During the Ming dynasty, such a tradition gradually faded out though this trend was a little overstated by the Western missionaries, who arrived in China later and embellished their own contributions in contrast to those of Ming science which preceded them.

If that is the case, then the study of the Shoushi calendar and also general enthusiasm toward traditional Chinese science was transfered from China to Korea under Emperor Sejong in the 15th century and in turn was transferred to Japan during the 17 th century, when astronomy in China was overwhelmed by Western Jesuit astronomy.

\section{Comparative phase}

The third turning-point was caused by Western influence in the 17 th century. The influence of the Western part of the globe reached China from time to time in its long history. For instance China received influence from India during the Tang and from the Islamic world during the Yuan dynasty, but these were supplementary to or merely juxtaposed side by side with the traditional approach and never seriously affected the genuine Chinese paradigms. It was not until the 17 th century that Chinese astronomy was dominated by Western influence for the first time in its history. The contents of astronomy was replaced totally by Western observations and theories, though it still maintained the general format and goal of traditional calendrical astronomy.

It was a shocking experience for the Japanese who had taken Chinese paradigms as a model but suddenly in the early 18 th century they realized that the underlying astronomical procedures of Chinese astronomy were all Western. After discovering this fact they promptly switched their model from China to the West.

Generally speaking, the third period is characterized as the period during which Chinese background and Western impact are always compared among East Asian people. Contemporary historians of science also approach this subject using the technique of comparative analysis.

\section{Modern phase}

The turning-point of the fourth phase would be the Opium War for the Chinese and Commodore Perry's visit to Japan for the Japanese in 
the middle of the 19th century. This is the real turning-point at which they abandoned the traditional framework of science and started to assimilate a Western framework of science. The quality and propensity of historians of science operating before and after this turning-point are quite distinguishable ; using terms familiar in Western historiography, we may classify them into " ancients " and " moderns". The ancients are still very close to the old Orientalist mood, in which genuine characteristically East Asian values are preserved and sought after, while the moderns are trying to look for ways of modernizing their countries in the socioinstitutional context. Modern investigation is usually directed towards the question of why East Asia lagged behind the West and did not attain a modern Scientific Revolution. While the ancients explored the possibility of alternative ways of science in their own traditions in a search for their identity, the moderns, critical of their own tradition, were anxious to find the quickest way of getting out of the traditional mold of thought and of reaching the forefront of contemporary science.

The two approaches alternately appear in recent history, neither one of which has come to be dominant. There must be some way to bridge these two groups of people and to synthesize the two approaches.

Shigeru NAKAYAMA, Tokyo University. 